\title{
A pedagogia social dos romances de amor dos "tempos da vovó"
}

\author{
Roberta Manuela Barros de Andrade \\ ERotilde Honório SiLva
}

\begin{abstract}
Resumo: A Coleção Biblioteca das Moças foi um conjunto de obras, de grande sucesso entre as camadas médias brasileiras, que reuniu a tradução de romances sentimentais franceses e ingleses de 1930 a 1960. Enfatizamos como certa visão de sociedade, conservadora e autoritária, se transforma, nas obras desta Coleção, em uma unidade ficcional que cristaliza ideologias e modela condutas, atingindo esferas sociais distintas de seu contexto de produção.
\end{abstract}

Palavras-Chave: Literatura de Massa; Romances Sentimentais; Mulheres; Produção; Ideologias.

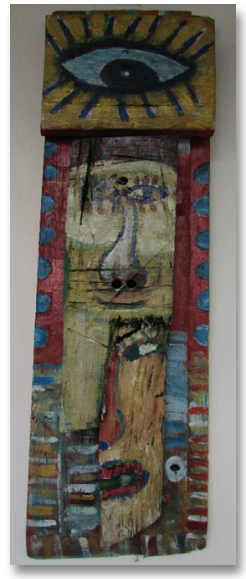

\section{The social pedagogy of love novels in "grandma's time"}

\section{Roberta Manuela Barros de ANDRADE}

Professora de Ciências Sociais e do Mestrado em Políticas Públicas e Sociedade da Universidade Estadual do Ceará/UECE. Coordenadora do Laboratório de Cultura, Consumo e Mídia/LABCCOM- UECE. manubarrosster@gmail.com

\section{Erotilde Honório SiLva}

Professora, Diretora de Comunicação e Marketing e membro de corpo editorial da Revista de Humanidades da Universidade de Fortaleza/UNIFOR. Pesquisadora do LABCCOM- UECE. eroh@uol.com.br

\begin{abstract}
The Young Women Library Collection was a set of works of great success among the Brazilian middle class, which brought together the translation of French and English sentimental novels between 1930 and 1960. We focus on how this collection presented a certain conservative and authoritarian vision of society, as a fictional message that crystallizes ideologies and models of behaviors, reaching different social spheres from those of its production context.
\end{abstract}

$\begin{array}{llr}\text { Keywords: } & \text { Mass } & \text { Literature; } \\ \text { Sentimental } & \text { Novels } & \text { Women; }\end{array}$ Production; Ideologies.

RECEBIDO EM: 27/01/2016

AProvaDo EM: 07/05/2016 


\section{ROMANCE, MULHERES E IDEOLOGIAS}

Senhores, agrada-vos ouvir uma bela história de amor e morte? Assim, inicia-se a saga de Tristão e Isolda, narrativa celta do século XII, que conta as desventuras de jovens que acabam morrendo, ao sucumbirem a uma paixão impossível. Com certeza, até hoje, nada no mundo nos agradaria mais do que ouvir a doce e trágica história de Tristão e Isolda. Destarte, o fascínio que cercava a população camponesa, que escutava em expectativa a dramática história desses dois seres apaixonados, sobreviveu aos séculos, materializando-se nos romances sentimentais ${ }^{1}$ contemporâneos, o mais popular gênero ficcional já produzido até o momento.

Os romances sentimentais, também chamados de romance "água com açúcar" ou "cor de rosa", ${ }^{2}$ são responsáveis por mais da metade de toda a produção de ficção vendida na América do Norte, o mais importante mercado cultural do mundo. Esta categoria de romance gera um montante anual de 1,52 bilhões de dólares em vendas, somente nos Estados Unidos, superando qualquer outro gênero disponível, hoje, no mercado (BUN, 2007; DUNGEE, 2003). Estes romances tanto são vendidos a preços populares em bancas de revistas e supermercados, com projetos gráficos simples e esquemas de marketing modestos, bem como podem ser encontrados nas grandes livrarias, com projetos gráficos ousados e investimentos publicitários vultosos.

Em 2000, 41,4 milhões de pessoas (incluindo 3,5 milhões de homens), $18 \%$ da comunidade de leitores norte-americana, estavam lendo um romance sentimental (REGIS, 2007). De acordo com Cox e Fisher (2009), em 2008, apesar da recessão econômica que fez cair a venda de livros (em termos de exemplares) em 10 bilhões e 714 milhões de dólares naquele ano, a venda de romances, nos

\footnotetext{
1 Um romance sentimental, gênero surgido em fins do século XIX, derivado dos romances folhetins (MEYER, 1996), é, antes de tudo, uma obra de ficção cuja temática aborda sentimentos e paixões. Trata-se, pois, de histórias de amor que concentram sua atenção sobre os estados emocionais e os conflitos internos das personagens muito mais do que sobre as ações externas (SAMONÀ, 1980). 2 Diferentemente das trágicas histórias de amor, típicas da baixa Idade Média, os romances sentimentais se caracterizam, contemporaneamente, pela presença inevitável do final feliz. Eis porque estes são chamados popularmente de romances "cor de rosa" ou romances "água com açúcar".
} 
Estados Unidos, gerou um montante de 1,37 bilhões de dólares. Neste mesmo ano, as obras editadas nesse gênero ficaram 252 semanas na lista dos mais vendidos do New York Times. No início do século XXI, 74,8 milhões de norte-americanos afirmavam estar lendo um ou mais romances sentimentais. Contudo, a prática de leitura de romances sentimentais não está restrita apenas aos Estados Unidos, se estendendo por toda a Europa e América Central e do Sul, passando pela China e pela Arábia Saudita e chegando até o Japão (MULHERN, 1989). Assim, o romance sentimental contemporâneo cruza fronteiras culturais, atingindo a mais de 114 mercados internacionais. Dentre esses mercados, encontra-se o Brasil como um espaço de consumo extraordinário para este tipo de publicação.

No nosso país, a trajetória dos romances sentimentais tem uma longa história. Nele, a difusão de romances de qualquer gênero se deu a partir do século XVIII, favorecida pela técnica da tradução. A prática de leitura dos romances sentimentais tornou-se um hábito cultural entre as elites por todo o século XIX (ABREU, 2003), sendo intermediada, principalmente, por editoras francesas de grande porte, que tanto mediavam a tradução de romances ingleses como produziam seus próprios autores. Entretanto, somente nas primeiras décadas do século XX, com a criação de editoras nacionais, $\mathrm{O}$ produto inicia seu processo de ampliação de público e deixa de ser privilégio apenas das elites, entrando no universo das camadas médias brasileiras. Esta expansão de nosso mercado editorial se dá não só com a ampliação do interesse pelo consumo de livros, mas, principalmente, pela expansão do mercado em direção a novas faixas de leitores.

O grande marco dessa trajetória é o lançamento da Coleção Biblioteca das Moças, da Companhia Editora Nacional (ANDRADE; SILVA, 2008, 2010, 2011; CUNHA, 1999). A Coleção Biblioteca das Moças foi um conjunto de obras que reuniu a tradução de romances sentimentais tanto de autores franceses como ingleses entre os anos de 1930 e 1960 no Brasil. O seu sucesso entre as camadas médias brasileiras foi tamanho que a Coleção tornou-se ícone de uma geração e sinônimo de romance sentimental neste período. É sobre estes romances que se detém, pois, a reflexão deste 
trabalho. São, portanto, os "livros do tempo da vovó" o objeto de análise aqui construído.

Para tal, partimos do pressuposto de que estes romances não devem ser encarados como mera opção de lazer para as mulheres deste período. Nenhum produto cultural pode pretender oferecer somente entretenimento. O entretenimento, como bem nos lembrou Adorno e Hockheimer (1985), transmite sempre uma representação, ideologicamente construída, sobre o social. A leitura é, assim, uma atividade socialmente condicionada por meio da qual os significados se organizam em um sentido (SARLO, 1990), mas não em um sentido qualquer. As representações contidas na literatura guardam dentro de si valores que, potencialmente, podem ser conservadores ou progressistas, a depender do contexto histórico em que a obra está inserida. Nesta perspectiva, o interesse em nos debruçarmos sobre esses romances está na percepção de que a leitura é uma prática social, historicamente situada que tanto constrói novas representações sobre o social como repercute visões consolidadas pela ordem dominante (CHARTIER, 1992).

Este é o caso dos romances sentimentais editados pela Coleção Biblioteca das Moças, que, ao fornecerem roteiros específicos de socialização para as suas leitoras, contribuíram para cristalizar visões de mundo, modelando as condutas de milhares de mulheres entre os anos de 1930 e 1960. No caso específico do Brasil, foi a partir dos usos de certo imaginário romântico, ali encontrado, que as elites brasileiras conseguiram uma importante via de difusão de ideias que conformavam a mulher a um claro papel de subordinação em relação ao homem, reforçando o ethos de uma sociedade patriarcal e autoritária.

Nessa perspectiva, nos indagamos: de que forma esta sociedade era descrita nestes romances? Qual era o lugar do homem e da mulher nesse universo imaginário? Que tipo de pedagogia social é ali construída? A metodologia utilizada para realizar tal empreitada foi a hermenêutica de profundidade de Thompson (1995), especificamente a sua análise sócio-histórica. Para fins deste trabalho, objetivamos enfocar como certa visão da sociedade, criada pelas elites de certo período, se transforma, nas obras desta Coleção, em 
uma unidade ficcional que atinge a outras esferas sociais distintas de seu contexto de produção. Trata-se, aqui, no fundo, de tentarmos entender, assim como pretendeu Max Weber, como certos valores sociais são construídos e que contextos históricos favorecem a esta construção.

Entretanto, diferentemente de Weber, empreendemos tal jornada baseadas no inestimável conceito de circularidade cultural de Ginzburg (1992). Este autor nos auxilia a compreender os valores sociais como unidades migratórias que não só se movem de uma plataforma de difusão para outra, mas, primordialmente, passam de uma classe (ou segmento de classe) para outra, modificando-se em sua passagem. Assim, o conceito de circularidade cultural nos ajuda a entender como certos valores, apesar de serem originários em certa classe ou segmento de classe, chegam a outras esferas sociais, sendo filtrados por seus novos destinatários, de acordo com seus próprios valores e condições de vida.

Dessa forma, utilizando o termo empregado por Darnton (1986), acreditamos que as correntes culturais se mesclam, movimentando-se para alto e também para baixo, produzindo valores sociais nômades, que transitam de um país para outro, de uma classe a outra, e, no caso específico dos romances da Coleção Biblioteca das Moças, das elites europeias para as classes médias brasileiras. Dito isso, convidamos, pois, os nossos leitores a iniciarem a jornada pelos romances de amor lidos nos "tempos da vovó".

\section{A COLEÇÃO BIBLIOTECA DAS MOÇAS E O MERCADO CULTURAL}

Nas décadas de 1930 a 1960, no Brasil, as moças de classe média urbana liam apaixonantes histórias de amor, reunidas pela Coleção Biblioteca das Moças. Obviamente, os anos de 1930 comportavam outras coleções, como a Coleção Azul ou os romances de sucesso que não pertenciam a nenhuma coleção, mas eram, indubitavelmente, os livros da Coleção Biblioteca das Moças os mais procurados. Esta Coleção foi uma grande aposta da Companhia Editora Nacional que deu certo. 
A Companhia Editora Nacional, fundada em 1920, abre uma nova era para o mercado editorial brasileiro. Até o último quarto do século XIX, este mercado era dominado por grandes livreiros e importadores como Francisco Alves, Garnier e Laemmert, que trabalhavam, em especial, distribuindo a produção literária estrangeira, traduzida em Portugal, e, em casos raros, publicando alguns autores brasileiros da época. Os pontos de venda eram quase inexistentes, as tiragens eram reduzidas e restrito o espectro de autores e obras publicadas. A maior parte da literatura se destinava a livros didáticos e de legislação brasileira (HALLEWELL, 1985). Assim, na entrada do novo século, os livros eram artigos de consumo apenas das elites brasileiras, mas o primeiro passo na transformação deste mercado já estava em curso.

Monteiro Lobato, junto com Octalles Ferreira, funda a Companhia Editora Nacional, trazendo uma verdadeira revolução para o campo editorial no Brasil. Nos anos 1920, a capa usual dos livros exibia apenas o título da obra, em papel amarelo ou cinza, mas os livros da Companhia Editora Nacional passam a utilizar ilustrações nas suas capas, muitas delas de artistas famosos da época, como Di Cavalcanti, Anita Malfatti e J. Prado. Internamente, há mudanças na diagramação das obras, no tipo de letra e na qualidade do papel. O consumo do livro se expande não só por conta de mudanças nas orientações editoriais, mas também, e não menos importante, porque se investe na divulgação e circulação deste bem cultural (MORAES, 1996).

O livro, a partir da Companhia Editora Nacional, deixa de ser artigo de luxo e passa a ser objeto de consumo das classes médias brasileiras. A Companhia Editora Nacional publica, assim, livros didáticos, ensaios sociológicos, contos, novelas, literatura infantil, crítica literária e de arte, crônica, ensaios e romances. ${ }^{3} \mathrm{~A}$ Coleção Biblioteca das Moças faz parte desta nova estratégia que

3 Como lembra Passiani (2002), o projeto literário desenvolvido pela Companhia Editora Nacional foi responsável pela criação de um novo habitus literário. A ação editorial desta empresa comprovou que a melhoria na distribuição do livro, a publicidade, a renovação gráfica, a escolha dos escritores a serem editados conseguiram levar o livro ao maior número possível de leitores. 
transforma o livro em mercadoria, ${ }^{4}$ expandido o seu público alvo para as mulheres da classe média urbana brasileira.

A Biblioteca das Moças, que fazia parte da Coleção Verde, publicou uma série de livros de amor, composta por aproximadamente 175 volumes, traduções de obras de autores franceses - em sua maioria - e ingleses, destinadas às mulheres das classes médias brasileiras urbanas, de maneira ininterrupta, entre os anos 1930 e 1960 do século XX. De acordo com a Companhia Editora Nacional, nos anos 1930, foram publicados mais de 900 mil exemplares; nos anos 1950, 2,9 milhões de exemplares; e, nos anos 1960, apenas 130 mil exemplares, sendo todos reedições. Este período foi o fim da era de ouro desta Coleção.

Nos anos 1980, a Companhia Editora Nacional reedita a Coleção, lançando no mercado 165 mil exemplares, mas tal empreitada não repete o sucesso de outros tempos e logo é abandonada pelos editores. Outros tempos exigem outras histórias. Em meados de 1970, o público-alvo desta coleção se modifica. Não se trata mais de leitoras oriundas das classes médias, mas de leitoras populares. Na década de 1970, Bosi (1991) comprova, em sua pesquisa sobre os hábitos de leitura das mulheres operárias em São Paulo, que estas elegeram sete livros da Coleção Biblioteca das Moças como seus prediletos.

Esta Coleção encontra lugar em um período caracterizado pelo crescimento não só de uma literatura nacional, mas também pela tradução em massa de livros estrangeiros, que começam a ser publicados pelas editoras brasileiras. A expansão do mercado editorial brasileiro se dá não só com a ampliação do interesse pelo livro nacional, mas, principalmente, pela expansão do mercado

4 O livro é uma invenção da tipografia que não nasce mercadoria e, sim, bem cultural. O fato de que, mesmo em seus primórdios, por detrás de seu processo de fruição, tenha havido a mediação da moeda, isto é, que tenha sido inserido em transações comerciais, não o torna, automaticamente, mercadoria. O livro, tal como a escultura e a pintura, é um bem cultural que somente a partir do século XIX pode ser caracterizado como mercadoria, graças ao desenvolvimento do capitalismo e das condições necessárias para a criação de um mercado dos bens simbólicos (HABERMAS, 1992). É neste momento que seu valor de troca supera o seu valor de uso, o que exige a criação de uma série de estratégias de mercado para o seu consumo. 
em direção a novas faixas de leitores. Neste novo nicho editorial, as mulheres eram o público alvo. Neste período, as mulheres ocupam mais a rua, isto é, circulam mais no espaço público e algumas delas começam a trabalhar fora do lar, apesar de muitas restrições (DEL PRIORI, 2006). Com o crescimento deste processo, as moças começam a frequentar as livrarias, comprando seus próprios livros.

A conquista deste público feminino está relacionada com estratégias editoriais que oferecem um conjunto de obras especialmente voltadas para as mulheres, enquadrando-as em coleções, definidoras de seu público leitor (TOLEDO, 2001). Ao invés de buscar um autor ou um título, as moças, que começam a frequentar as livrarias, perguntam pelos livros que vão sendo publicados nas coleções a elas destinadas. O circuito de publicidade e divulgação das editoras e livrarias e as recomendações divulgadas em jornais e revistas, por pessoas que se destacavam no universo letrado, acabam por colocar a Coleção Biblioteca das Moças como uma opção "saudável" de leitura para as mulheres das classes médias urbanas brasileiras.

\section{A PEDAGOGIA SOCIAL DAS HISTÓRIAS DE AMOR DE OUTRORA}

Para os circuitos de informação presentes neste período, a Coleção era encarada como pedagógica, sendo considerada, inclusive, por muitos, como romances de formação. Tal classificação dá ao gênero romance sentimental certa "dignidade literária" porque tornaria a sua leitura uma mediação de um processo de aperfeiçoamento moral do indivíduo burguês. Se os romances sentimentais destinados às jovens da classe média não acompanhavam os dilemas morais dos protagonistas desde a infância até a idade adulta, nem sequer apontavam a profundidade destes dilemas, como o caso do jovem Wilhelm, de Goethe, ou de David Copperfield, de Dickens, os romances da Coleção guardam uma característica básica: o aprendizado social que a entrada da jovem mulher no mundo adulto requer. 
Os romances de formação são aqueles de cunho pedagógico, que indicam o lugar moral ao qual seus leitores devem pertencer a partir das características físicas e psicológicas das personagens e do desenrolar da ação, trazendo sempre um claro alerta social. Madame Bovary, de Flaubert, se enquadra dentro desta tipologia. O famoso escritor francês escreve a trágica história de Madame Bovary, a fim de alertar as mulheres sobre os perigos da leitura de romances sentimentais que transformam a mente e o coração das simplórias mulheres burguesas, impulsionando-as a almejarem para si um casamento embalado pela aventura e pelo prazer que só encontra lugar na fantasia telúrica das romancistas. A mensagem é clara: sonhos de completude, realização, encontros e partilhas ferem a ordem burguesa, desintegrando sua principal instituição - o casamento.

Entretanto, a pedagogia inclusa nos romances desta Coleção não é tão complexa. Ali, o que impera são conceitos polarizados. O bem e o mal estão delineados, em geral, de forma muito clara. Os romances desta Coleção enaltecem, em suas heroínas, as virtudes cristãs, destacando-se, dentre elas, a renúncia, a caridade, a bondade, a dedicação, a delicadeza, a modéstia, o recato, o decoro e, em relação aos homens, a honra, a força, a inteligência, o patriotismo, o cuidado com a coisa pública. Os homens são, em geral, fortes, autoritários, mundanos, senhores de si e de seus domínios. Aqui, uma pedagogia das atitudes se instala.

Na relação entre os protagonistas, cabe à mulher ensinar ao homem a ser menos autoritário, egoísta e despótico, mais cristão e mais solidário, e a ele ensiná-la, quando muito, a ser menos orgulhosa e rancorosa. Lembramos que o orgulho e o rancor são, aparentemente, os dois únicos "defeitos" que podem ser computados em heroínas tão moralmente superiores. Em geral, os dois casam-se, podendo ser felizes para sempre ou ocorrerem conflitos até que a aprendizagem social seja incorporada e a relação encontre seu equilíbrio. Seja qual for o conflito existente no casamento, cabe à mulher dar o primeiro passo na relação para que a reconciliação aconteça, cabe a ela se adaptar ao temperamento do cônjuge e tentar, com a sua influência generosa, modificar 
gradativamente seus defeitos de caráter. É esta pedagogia do casamento que se delineia:

É preciso que um grande amor recíproco os una, ao menos,
é preciso, Milady, que tenha bastante coragem, abnegação,
devotamento, para suportar os erros do seu marido, os de-
feitos do seu caráter e fazer penetrar, pouco a pouco, a sua
influência na sua alma, para transformá-la (DELLY, 1955b,
p. 81).

Não é à toa, pois, que alguns autores dessa coleção, como M. Delly, ${ }^{5}$ Henry Ardel $^{6}$ e Guy Chantepleure, ${ }^{7}$ tenham o selo de aprovação da Igreja e da Escola. Nestes romances, era possível incorporar valores compatíveis com os mecanismos de dominação da sociedade maior, patriarcal e conservadora que se faz soberana entre os anos de 1930 e 1960 do século XX, no Brasil e mundo afora. Os princípios do patriarcalismo estão, claramente, presentes nas obras deste período. Estes descrevem um mundo no qual há um alto grau de dependência econômica e social não só das mulheres, mas de todos os demais membros do grupo familiar em relação à autoridade do herói, exercida de forma soberana, sem qualquer possibilidade de confrontos ou partilhas.

O pai ou marido detém o poder sobre a propriedade familiar e dispõe dos bens de outros membros a seu bel prazer. Correlata à autoridade sobre os bens, cabe-lhe a obrigação de se responsabilizar pela sobrevivência dos membros do grupo doméstico, mantendo uma condição de tutela sobre as mulheres (AGUIAR, 1997). Neste sentido, as mulheres descritas por esta Coleção desenvolvem "virtudes" que se adaptam a esta ordem de controle social, embora esta ordem não esteja apenas restrita à ação

5 M. Delly é o pseudônimo de dois irmãos gêmeos franceses, católicos fervorosos chamados Frédéric Henri Petitjean de la Rosière (1870-1949) e Jeanne-MarieHenriette Petijean de La Rosiére (1875-1947). Entre 1935 e 1960, M. Delly é a autora que alcança o maior número de obras e edições, com trinta títulos publicados.

6 Henri Ardel (1863-1938) é o pseudônimo de Berthe Abraham, escritora francesa que escreveu ao todo 28 romances, publicando nove títulos pela Coleção Biblioteca das Moças.

7 Guy Chantepleure (1870-1951) é o pseudônimo de Jeanne-Teresa Violet, escritora francesa. Foram sete os títulos publicados pela Coleção Biblioteca das Moças, e três livros adaptados para o cinema, entre as décadas de 1910 e 1950. 
feminina. Estes livros narram uma sociedade imaginária na qual o controle social sobre os seus membros, homens ou mulheres, é uma constante.

A Coleção reproduz de maneira óbvia a ideologia funcionalista ${ }^{8}$ hegemônica nas classes dominantes na primeira metade do século passado. Na visão de Elinor Glyn, ${ }^{9}$ uma das autoras mais populares desse período, as leis sociais dominam os homens com absoluta firmeza e tudo o que eles podem fazer é submeter-se a elas. Nesta ordem, alguns homens têm uma inclinação natural para exercer determinadas funções no social e as classes abastadas teriam esta habilidade inata, reafirmada a cada nova geração, para ocupar postos de comando no mundo social. Aqueles, pois, que aspiram posições que não lhes cabem quebram a harmonia inata da ordem natural, produzindo a instabilidade e a desordem social.

A lei imutável é que ninguém se assegura uma posição, a menos que esse alguém, seja homem ou mulher, não tenha nascido pra isso. Em não existindo harmonia, nada perdura. Porque a Inglaterra neste momento está fora da harmonia é que se verificam tais agitações. A senhora e a sua estirpe foram talhadas para a posição que sustentam há centenas de anos, e essa a razão de inda aí permanecerem; e sua influência, bem como a própria raça, tornaram a Inglaterra tão poderosa (GLYN, 1956, p. 152).

Nesta perspectiva, os conflitos sociais surgem, em Elinor Glyn, tais como refletidos por Émile Durkheim. Em sua narrativa, os indivíduos aspiram ocupar postos na sociedade aos quais não possuem nem competência nem habilidades para alcançar. As classes populares, indisciplinadas, não conhecem mais o lugar ao qual pertencem. As crises se explicam pela falta de ajuste entre as diversas classes do organismo social e se constituem em patologias do sistema. Estas classes, insaciáveis, aspiram ao que não lhes pertence por direito, e o caos social se instala. Por outro lado, as classes

8 O funcionalismo é uma corrente sociológica que está associada, em seus primórdios, à Emile Durkheim. Esta corrente enxerga a sociedade como um organismo vivo, no qual os órgãos, as instituições sociais, deveriam funcionar de maneira harmônica. Qualquer desvio desta ordem é considerado uma patologia a ser extirpada pelo sistema.

9 Elinor Glyn (1864-1943) foi uma romancista e roteirista inglesa, sendo a escritora mais controversa do período. Publicou treze livros por esta Coleção. 
"altas" estão no topo da pirâmide social, porque nasceram com habilidades e competências naturais que lhes permitem ali permanecerem. Assim, o melhor governo do mundo é aquele em que cada um conhece seu lugar, de acordo com suas diferenças naturais.

Todas as classes estão se esquecendo de suas disciplinas, e, sem que se ajustem ao que aspirem, esforçam-se por agarrar no que pertence à outra classe...A lição que se deduz é que, para o bem público, quem não estiver na altura de qualquer cometimento, a ele não deve aspirar. Um certo e sempre crescente número de indivíduos estão agarrando em coisas para as quais sua classe não foi ajustada... E as classes médias estão agarrando naquilo que acreditam ser a nobreza e ridículas pretensões quanto ao nascimento e estirpe, e se esquecem do trabalho honesto da classe de que surrupiam tais coisas. De outro lado, as classes inferiores estão agarrando em tudo o que podem, mercê do lastimável rebaixamento das outras duas, e vivem a gritar que todos os homens são iguais. Se descermos a coisa práticas, de idéias comunistas em abstrato, sobrecarregado estará o mais recente dos seus foguistas com trabalho que vai muito além da sua capacidade (GLYN, 1956, p. 153).

Entretanto, se nas primeiras décadas, as histórias davam conta do amor entre nobres e aristocratas, nas décadas seguintes, as classes médias aparecem nas histórias. É a entrada do mundo urbano e industrial nas narrativas. Dos castelos passa-se aos escritórios, das carruagens e dos iates aos carros e demais transportes públicos, como os bondes e táxis. O centro da narrativa se desloca, o mundo privado, agora, tem maiores contatos com o mundo público. De protagonistas nobres, passamos a gerentes de lojas, médicos, vendedores, militares, advogados, professores, manicures. Porém, o universo das classes médias deve obedecer a uma determinada gramática moral que despreza os ícones da cultura de massa daquele momento: o cinema, os cosméticos, a vestimenta que delineia as curvas femininas.

"O casamento de Ana", de Merrel (1955),,10 uma das autoras mais populares do período, narra os infortúnios de um casamento precipitado. O desemprego do protagonista, os pequenos conflitos

10 Concordia Merrel (1866-1963) foi modelo fotográfico e escritora. Publicou 13 livros por esta Coleção. 
domésticos, os maus tratos do homem que "perde o comando da casa" e passa a ser sustentado pela mulher, as discórdias em relação ao uso do dinheiro, agora restrito, são temas importantes na narrativa. Ali, há até mesmo a possibilidade de traição, que não se concretiza, mas aparece de forma viva no romance. De toda forma, a anti-heroína, a que quase faz o "homem pecar" frequenta os lugares da moda, vai ao cinema, usa maquiagem e roupas reveladoras, é retratada como vulgar, fútil e sem moral. Ao final, contudo, a mulher tudo contemporiza, o provedor volta a prover, uma criança nasce e a vida conjugal se equilibra, porque, segundo a autora, "os casamentos são feitos no céu, mas, devem ser vividos na terra".

Apesar disso, não foram as obras que tratavam do universo das classes médias urbanas que marcaram a Coleção, tornando-a ícone de uma época, mas sim sua ambientação na Europa nobre e aristocrática. Este sucesso editorial se deve a duas grandes e, em muitos sentidos, opostas coletâneas de obras desta Coleção: as assinadas por M. Delly e as por Elinor Glyn. Como em qualquer obra popular que pertença a esta Coleção, os livros de M. Delly retratam sempre a luta feminina por conservar sua honra intacta num mundo cheio de armadilhas. Em M. Delly, as heroínas vivem em um universo no qual é proibido sair de casa sozinha, conversar com estranhos, ficar a sós com homens e manifestar desejos sexuais. O sexo é camuflado, sabe-se que ele é parte constituinte da vida conjugal, o gerador de filhos, mas esse fato natural da espécie não se comenta em público ou em particular (DEL PRIORI, 2006). As obras de M. Delly são as mais indicadas pela Igreja e pela Escola, constituindo a leitura ideal para as "moças de família".

Elinor Glyn, ao contrário, é ignorada pela cultura oficial, lida nas dobras do travesseiro, à meia luz e comentada entre sussurros pelas suas jovens leitoras. As protagonistas de Elinor Glyn, ao contrário das recatadas damas dellyanas, fumam, frequentam livremente os espaços públicos, tem atitudes morais ambíguas e expressam sem amarras suas opiniões sobre economia, política e cultura. É Elinor Glyn a responsável pela criação do termo "it" que designa, em suas obras, a primeira metáfora da literatura sentimental para atração sexual. Em seus romances, as relações 
homem-mulher aparecem sempre carregadas de forte apelo sexual, estratégia narrativa inédita para o período.

Ambas as escritoras, apesar de estabelecerem diferentes modos de contar suas histórias de amor, são retratistas do universo da alta sociedade, em geral, a relacionada à nobreza. Cunha (1993) acredita que isto se deve ao fato dos gostos burgueses daquele período estarem relacionados à França: vestimentas, culinárias, língua, mobiliário, hábitos sociais e modas. Todavia, histórias ambientadas na França não são hegemônicas nesta Coleção. O universo descrito por Elinor Glyn e várias outras autoras de sucesso desta Coleção se desenrola na Inglaterra e não na França, tal como em Bertha Ruck ${ }^{11}$ e em Concordia Merrel. Então, talvez o que mova a apreciação de nossas leitoras pelas histórias de nobres cavalheiros e gentis damas seja o imaginário de uma elite, prenhe de privilégios, que subjaz neste universo. E nenhuma elite é mais privilegiada do que a nobreza. Ressaltamos, aqui, a ideia de que o enaltecimento da nobreza se materializa nas elites brasileiras, do Império à República. Holanda (1997), ao se referir à sociedade dos anos de 1930, no Brasil, salienta que este apego aos valores da "noblesse", decadente ou não, é forte em nossas elites. Nossas elites, não possuindo títulos de nobreza, historicamente, os substituem por anéis de bacharéis. Estes simbolizam, então, o desejo de resgate desta nobreza almejada e cremos que os romances sentimentais deste período, a entrada imaginária das classes médias neste universo.

Em outra perspectiva, o processo de urbanização, vigente nos anos de 1930, tão louvado pelas elites, não se faz para todas as classes sociais da mesma forma. Respiram-se ares de modernidade no país, a crise da sociedade agrária se agrava, a industrialização toma impulso, cresce a indústria de base com Getúlio Vargas, o comércio se amplia, inicia-se um acelerado processo de urbanização. Os casarões são demolidos, as ruas alargadas, o bonde se

11 Bertha Ruck também retrata constantemente o universo das classes médias urbanas. A cena romântica de "Noiva oficial" se passa toda em uma "Agência Oriental de Embarques", nas quais circulam a Srta. Trant e o Sr. Walters, respectivamente, a datilógrafa e o gerente da empresa, que se enamoram entre memorandos e máquinas de escrever. 
instaura como símbolo de uma nova era. Porém, nos subterrâneos, como lembra Sevcenko (1995), a oferta de mão de obra é abundante em comparação com os postos de trabalho disponíveis, os salários se deterioram, a taxa de desemprego aumenta, os alojamentos e moradias não dão conta das demandas por urbanização, as doenças relacionadas à falta de higiene proliferam, há carestia e fome entre as classes mais humildes.

Não é, pois, à toa que as nossas jovens leitoras de classe média urbana, pressionadas pelas demandas dos que estão embaixo na hierarquia social, desejem ardentemente histórias de amor que tratem de outro tempo, de outra época, em outros países, onde o luxo impere, seguindo a tradição folhetinesca das obras de Machado de Assis e José de Alencar, já absorvida pelas mulheres leitoras deste período. Esse imaginário de "luxo" se materializa nos brocados, nas sedas, nos aparadores, nas poltronas, nos abajures, nos vasos de flores, nas carruagens, na eficiente e servil criadagem, nas festas suntuosas, nas mesas elegantes e fartas tão abundantemente descritas:

Do lustre de Veneza, onde todas as velas estavam acesas, se espalhava uma luz viva sobre toda a sala, iluminando as tapeçarias de Bruxelas, onde cisnes vogavam sobre os tanques azuis, os móveis preciosos de incrustações de marfim, todas as maravilhosas coisas aí dispostas (DELLY, 1955b, p. 94).

O número de pratos era extraordinário. Parecia suficiente para um jantar completo, e Tâmara pensou, por um momento, como seria possível ingerir ainda outros alimentos depois. Quando chegou a vez de sentar-se à mesa, a jovem inglesa viu-se colocada entre um velho príncipe de elevada estatura, e um diplomata. Os vistosos uniformes dos homens e os ricos colares de pérolas das senhoras atraíram a sua atenção, oferecendo um agradável espetáculo para os seus olhos. Aquelas pérolas davam para o resgate de um rei (GLYN, 1955, p. 79).

Quem, então, lê os romances publicados por essa Coleção? Estes são as escolhas mais populares entre as normalistas, mulheres de classe média que frequentavam a Escola Normal, correspondendo, à época, ao ideal de boa conduta da mulher brasileira. Elas eram divididas em dois grupos: as que almejavam ser professoras (umas das poucas ocupações socialmente respeitáveis para 
as mulheres da época) e as que desejavam se preparar para o casamento. Assim, para este extrato social, M. Delly era a autora mais popular, indicada pela Igreja e pela Escola, ${ }^{12}$ recebendo, portanto, respaldo das famílias de classe média urbana deste período (CUNHA, 1999).

Se cabia à Igreja e à Escola indicar as leituras apropriadas para as jovens, em M. Delly, cabia ao marido a vigilância cuidadosa da leitura de suas eleitas. Para essa autora, este, inclusive, é o dever do marido cristão, cuja atenção criteriosa aos hábitos de leitura de sua parceira deveria levar em consideração a sua natural delicadeza de sentimentos. Os livros são tanto formadores da alma como também, perigosos. Muitos livros não possuem, como afirma Delly (1955c), em "Orieta", em "Corações Inimigos", "palavras chocantes" ou "cenas arriscadas", mas guardam consigo uma imoralidade escondida perfidamente. Era, pois, preciso uma alma delicada, uma inteligência sutil para perceber o veneno destilado nas páginas, disfarçado sob aparência inocente.

Via-se, assim, a moça associada ao trabalho do marido a
quem, aliás, muito interessava a inteligência arguta e viva
de Valderez. Era agora nesse terreno histórico e literário que
eles continuamente se encontravam. Elias parecia compra-
zer-se em conversar com a esposa, guiá-la em suas leituras,
e isso com um tato, um cuidado moral, que muito deram que
pensar ao cura de Vrimères, quando Valderez lhe comuni-
cou que o senhor de Ghiliac somente lhe autorizara a leitura
de dois dos seus próprios romances (DELLY, 1959, p. 71).

Nesses romances, o modelo feminino que predomina é o da mulher pura e restrita ao lar, sempre amarrada aos grilhões de seu cônjuge. Neste ambiente, as principais ocupações das protagonistas são ornar vasos, bordar, pintar, escrever poemas, rezar e, algumas, cavalgar, jogar golfe e tênis ou caminhar. M. Delly, por exemplo, teme a vida fora do lar, que nomeia como mundana, cheia de perigos e armadilhas, repleta de falsos encantamentos que poderiam tornar a mulher vaidosa, coquete e fútil. Na esfera pública, cabe-lhes apenas usufruir de suas expressões artísticas,

12 Não é só M. Delly que enaltece tais valores, em menor grau, vemos a mesma orientação em Guy Chantepleure, em Florence L. Barclay, Henri Ardel, dentre tantos outros. 
tais como concertos e apresentações teatrais, e exercer os deveres da sociabilidade que sua posição social exige, em festas e eventos públicos. ${ }^{13}$

A exceção à regra das autoras que retratam o mundo da alta sociedade está em Elinor Glyn, cujas heroínas transitam em cenários nos quais podem trabalhar fora de casa, participar da vida política e terem uma vida amorosa mais livre das convenções sociais, inclusive convivendo com problemas sociais típicos da vida urbana. Em "O it", tais problemas são citados, pela primeira vez, de forma direta nos romances sentimentais. O irmão de Ava, a protagonista da história, é viciado em ópio e cocaína e a própria Ava, de linhagem aristocrática, é obrigada a abandonar a sua vida desocupada para ganhar o seu sustento. Assim, ao adentrar ao mundo do trabalho, ocupação relegada, em sua classe, às mulheres inferiores, Ava reconhece sua vida anterior inútil e sem predicados, que não lhe permitiria ganhar o sustento de forma honesta:

Sua inteligência já a fizera compreender que só o acaso do nascimento a diferenciava das demais empregadas, sendo que muitas destas teriam muito mais competência do que ela, para desempenharem suas respectivas funções. Aquelas moças, afinal de contas, realizavam alguma coisa útil, exercitavam em parte sua inteligência; e, se o nascimento fosse circunstância de valor, deveria torná-la melhor e, não, pior do que elas. Empregaria todos os esforços para fazer bem feito o seu trabalho, sem murmurar nem lastimar-se a si mesma (GLYN, 1940, p. 33-34).

Porém, ao contrário da "liberada" Elinor Glyn, para M. Delly, as mulheres só devem tomar para si uma profissão quando acometidas por uma vocação irresistível. Elas não estão preparadas, por suas almas delicadas, para a competitividade do mundo do trabalho, dominado por homens. Para não morrerem de fome, depois de tantos estudos custosos e difíceis, são obrigadas a perderem sua delicadeza de espírito. A autora guarda ainda uma admiração por mulheres que procuram sua independência, não ficando à mercê

13 A única de suas protagonistas que exerceu uma profissão liberal foi Ariana, em "Foi o Destino". Mas, a profissão não foi uma escolha de Ariana, que teria preferido uma ocupação artística, mas uma imposição de seu pai, preocupado com questões pecuniárias. Ariana era uma advogada de sucesso, mas quando se casa, abandona o exercício da profissão (DELLY, 1954). 
de seus pais ou maridos ricos. Se precisarem trabalhar, porém, que o façam em profissões que conservem sua feminilidade, como a enfermagem, o magistério e a confecção de roupas.

As mulheres de ciência, por exemplo, afirma Delly (1960), em "Magali", apesar de possuírem méritos, correm o risco de se tornarem "sabichonas" e "pedantes". A ida da mulher ao mercado de trabalho, impulsionada por questões econômicas, corre o risco de desintegrar a família. Esta é uma tendência estrangeira, importada do espírito norte-americano. Às mulheres realmente cristãs cabe não ouvir o canto da sereia, se descuidando do lar e de sua verdadeira vocação. As obras de M. Delly não darão guarida a "revolucionárias de saias". Este é o caso de Bárbara, em "Escrava ou rainha", que foi expulsa da propriedade de Sérgio, o príncipe Ormanoff, porque partidária de ideias comunistas. Nestes romances, os surtos revolucionários devem ser contidos. A melhor postura que se deve ter perante o mundo é não lutar contra ele, mas, sim, ser com ele condescendente e acrítico (DELLY, 1955a). Esta mesma linha de pensamento é, em maior ou menor grau, compartilhada por outras escritoras desta coleção, inclusive, pela aparentemente mais revolucionárias delas, Elinor Glyn:

O mundo, disse acomodando-se na cadeira, é um lugar muito agradável para quem o sabe ver como êle é na realidade, porém, jamais pode agradar a quem pretender lutar com êle; não se deve ser intolerante, nem muito propenso à crítica. É preciso observá-lo a fundo, e ser condescendente com os que nele vivem (GLYN, 1955, p. 67).

Seguindo essa lógica, em M. Delly, o movimento feminista só é aceitável, em alguns casos, quando se propõe a "fazer reformas úteis e boas", mas deve ser acompanhado de perto pelos riscos de sua radicalização. Daí o cuidado que se deve ter ao travar relações em sociedade. Não basta somente se vestir bem, ter um vocabulário ousado e mundano e conhecer pessoas de prestígio. É necessário ter linhagem. Esta noção de que a vida em sociedade se dá a partir do momento em que todos saibam o lugar que devem ocupar nas hierarquias sociais não está somente presente em M. Delly, mas em tantas outras autoras do seu tempo. Elinor Glyn, por exemplo, compartilha do mesmo ponto de vista, que pode ser percebido pela apreciação de Tamara, pela nobreza russa: 
Uma simplicidade tão absoluta e um encanto igual só seriam possíveis em uma sociedade em que ninguém pudesse "penetrar", onde todos os seus membros lhe pertencessem por direito de nascimento. Ali não havia lugar para a "profissão" exercida por certas senhoras inglesas, de grandes títulos de nobreza, e sem nenhum dinheiro, de apresentar em sociedade e às suas amigas qualquer pessoa, embora inconveniente, a troco de uma dourada recompensa (GLYN, 1955, p. 81).

Porém, M. Delly, mais radical do que Elinor Glyn, em sua "filtragem social", não aprecia a emergente classe burguesa, que quase sempre é alvo de ironias por parte de seus nobres cavalheiros. O "homem que se faz" é uma invenção das Américas. É horrível ver, como afirma M. Delly, em "Magali", introduzir-se na sociedade "ricaças de ontem", em cuja árvore genealógica está presente progenitores que vendiam "latas vazias de conserva", nas ruas de Nova York, e, depois, preparavam ingredientes para encher estas latas, em grossos afazeres. Elinor Glyn, apesar de produzir suas obras no mesmo tempo histórico de M. Delly, constrói variações a essa ideologia.

Em "O it", John Gaunt, seu protagonista, representa o extrato dos desprezíveis "novos ricos" de M. Delly, que não só adveio das classes populares, como também de seus setores mais carentes. John Gaunt conheceu a miséria e o trabalho duro, os bordéis e o chão das fábricas. Ao contrário dos nobres e ociosos cavalheiros de M. Delly, com suas fortunas herdadas, John Gaunt trabalha no Centro de Londres, onde ganha milhões a cada dia, sendo, neste mundo, o soberano incontestável. Se, em M. Delly, o contexto no qual a ação se desenrola é quase sempre o da aristocracia em todo o seu esplendor, Elinor Glyn, apesar de retratar com glamour o mundo das festas, dos bailes, das visitas sociais, revela uma preocupação com uma estrutura social que apresenta sinais de decadência. Em seus romances mais modernos, já aloca a figura do burguês como o novo integrante deste círculo sagrado, desta vez, não definido pelo nascimento ou pela tradição, mas por mérito próprio:

John Gaunt elevara-se da mais ínfima camada popular; suas mais antigas recordações eram as de uma casa imunda em Bowery e de sua avó ébria, a tagarelar sobre os tempos antigos e sobre o esplendor de sua vida antes da "queda". O neto sempre achara que a queda fora em verdade muito 
grande, mas por exclusiva culpa dela; todavia, quem fosse a avó ou donde ela proviesse, eram coisas que não o interessavam. No que achava interesse era no fato de ter mais força que os outros meninos e dar-lhes mais valentes surras. Aos dez anos vendia jornais e dedicando-se, ora a uma, ora a outra coisa, ia-se educando a si próprio, sendo que, quando chegou aos quarenta, e surgiram interessantes sucessos em sua vida, não só já havia acumulado grande fortuna, como também era pessoa de apurada cultura (GLYN, 1940, p. 1).

Assim, enquanto em M. Delly, o caráter dos protagonistas segue claramente a moral instituída do período, há, em Elinor Glyn, linhas de fuga nesta construção. Existem ambiguidades em suas personagens que, se não rompem exatamente com a gramática social do período, abrem possibilidades de pensar o social que não estavam em pauta à época. Esta autora é, em certa medida, revolucionária; porém, a tentativa de ruptura com os padrões da época é inócua, pois, ao fim da narrativa, tudo volta ao equilíbrio inicial. Trata-se, então, nas melhores análises de Eco (1988), de uma estrutura reformista.

Nesse contexto, as autoras da Coleção não produzem apenas divertimento vazio e apolítico para as jovens senhoras do período. As obras literárias, como qualquer outro bem cultural, carregam consigo uma visão de mundo, que particulariza certos interesses sociais em detrimento de outros. Neste cenário, entre os anos 1930 e 1960, os romances da Coleção Biblioteca das Moças serviam, para suas ávidas leitoras, de válvulas de escape para uma vida na qual a maior parte dos desejos de independência feminina era sufocada pela estrutura social. Somente restava como alternativa às mulheres desse período a busca por um amor que as libertasse de uma estrutura repressora, ainda que esta liberdade fosse encontrada nos laços do matrimônio, o que significava a continuidade do processo repressivo (RADWAY, 1987).

Está posta, pois, de forma clara a pedagogia desta Coleção. É, assim, ilusório pensar que estes romances retratam apenas história de amor. Eles narram, particularmente, as ideologias das classes dominantes, que, sendo dominantes, se assemelham em qualquer país do mundo. No Brasil, estes livros agradavam aos homens de letras (por subordinarem a mulher a papéis sociais fixos), aos homens da política (por construírem uma ordem social 
das elites para as elites) e aos homens da economia (por fazerem soar aos ouvidos das classes médias os arautos do luxo a que um dia poderiam ascender). Toda a ordem social descrita nestes romances está, portanto, equilibrada, reforçando os ideais de uma elite que são representados majestosamente pela literatura sentimental da época, na qual se revelam os interesses de conservação de uma sociedade autoritária, patriarcal e impositiva.

\section{REFERÊNCIAS}

ABREU, M. Os caminhos dos livros. Campinas: Mercado das Letras, 2003.

ADORNO, T. W.; HORKHEIMER, M. A dialética do Iluminismo. Rio de Janeiro: Zahar, 1985.

AGUIAR, N. Perspectivas feministas e o conceito de patriarcado na sociologia clássica e no pensamento sociopolítico brasileiro. In: Gênero e Ciências Sociais. Rio de Janeiro: Rosa dos Tempos, 1997.

ANDRADE, R. M. B.; SILVA, E. H. O império das emoções e a literatura sentimental no Brasil. Contracampo, Niterói: v. 22, p. 32-44, 2011.

. Corpos que falam: erotismo, amor e paixão no romance sentimental. Comunicarte, Campinas, n. 40, v. 30, p. 9-25, 2010.

Os livros do coração: uma análise dos romances sentimentais do século XX. Contracampo, Niterói, v. 18, p. 203224, 2008.

ARDEL, H. A ausência. São Paulo: Nacional, 1956.

BARCLAY, F. L. Enquanto é tempo de amar. São Paulo. Nacional, 1959.

BOSI, E. Cultura de massa e cultura popular: leituras operárias. Rio de Janeiro: Vozes, 1991.

BUN, J. C. The effects of romance novel readership on relationship beliefs, romantic ideals and relational satisfaction. 2007. Tese (Doutorado) - Boston College, Boston, MA, 2007. 
CHANTEPleURE, G. de. Noiva. São Paulo: Nacional, 1947.

CHARTIER, R. Textos, impressões, leituras. In: HUNT, L. A nova história cultural. Rio de Janeiro: Martins Fontes, 1992.

COX, A.; FISHER, M. The Texas billionaire's pregnant bride: an evolutionary interpretation of romance fiction titles. Journal of Social, Evolutionary, and Cultural Psychology, v. 3.4, p. 386401, 2009.

CUNHA, M. T. S. Armadilhas da sedução: os romances de M. Delly. Belo Horizonte: Autêntica, 1999.

Biblioteca das moças: contos de fada ou contos da vida?. São Paulo: EdUSP, 1993. (Cadernos de Pesquisa, n. 85).

DARNTON, R. O grande massacre de gatos. Rio de Janeiro: Grall, 1986

DEL PRIORI, M. História do amor no Brasil. São Paulo: Contexto, 2006.

DELLY, M. Magali. São Paulo: Nacional, 1960.

Entre duas almas. São Paulo: Nacional, 1959.

Escrava ou... rainha. São Paulo: Nacional, 1955a.

Lady Shesbury. São Paulo: Nacional, 1955b.

Orieta. São Paulo: Nacional, 1955c.

Foi o destino. São Paulo: Nacional, 1954.

DUNGEE, P. M. I. Integrated marketing communications at Harlequin Entreprises: the marketing of happily ever after. 2003. Dissertation (Master's Degree) - Seton Hall University, New Jersey, 2003.

ECO, U. O super homem de massa. São Paulo: Perspectiva, 1988.

GINZBURG, C. O queijo e os vermes. São Paulo: Companhia das Letras, 1992.

GLYN, E. Por quê? São Paulo: Nacional, 1956.

Seu único amor. São Paulo: Nacional, 1955. 
O it. São Paulo: Nacional, 1940.

HABERMAS, J. L'espace public. Paris: Payot, 1992.

HALLEWELL, L. O livro no Brasil. Rio de Janeiro: T. A Queiroz, 1985.

HOLANDA, S. B. Raízes do Brasil. Rio de Janeiro: Companhia das Letras, 1997.

MERREL, C. O casamento de Ana. São Paulo. Nacional, 1955.

MEYER, M. Folhetim. Rio de Janeiro: Companhia das Letras, 1996.

MORAES, P. B. de. Monteiro Lobato e a constituição das editoras nacionais. In: REIS, E.; ALMEIDA, M. H. T. de; FRY, P. (Orgs.). Política e cultura: visões do passado e perspectivas contemporâneas. São Paulo: Hucitec/ANPOCS, 1996.

MULHERN, C. I. Japanese Harlequin romance as transcultural woman's fiction. The Journal of Asian Studies, Michigan, USA, 48, n. 1, 1989.

PASSIANI, E. Na trilha do Jeca: Monteiro Lobato, o público leitor e a formação do campo literário no Brasil. Porto Alegre: EdUFRGS, 2002. (Sociologias, n. 4).

RADWAY, J. Reading the romance: women, patriarchy and popular literature. London: Verso, 1987.

REGIS, P. A natural history of the romance novel. Philadelphia: University of Pennsylvania Press, 2007.

RUCK, B. Noiva oficial. São Paulo: Nacional, 1958.

SAMONÀ, C. Los códigos de la novela sentimental. In: RICO, F. Historia y crítica de la literatura española. Barcelona: Crítica, 1980.

SARLO, B. La narrativa sentimental: el género desde la perspectiva sociocultural. Genre studies in hispanic literature. Michigan: University of Michigan/Center of Latin American and Caribbean Studies, 1990.

SEVCENKO, N. Literatura como missão: tensões sociais e criação cultural na Primeira República. São Paulo: Brasiliense, 1995. 
THOMPSON, J. B. Ideologia e cultura moderna: teoria social crítica na era dos meios de comunicação de massa. 4. ed. Petrópolis: Vozes, 1995.

TOLEDO, M. R. de A. Coleção atualidades pedagógicas: do projeto político ao projeto editorial (1931-1981). 2001. Tese (Doutorado) - Departamento de Educação, Pontifícia Universidade Católica de São Paulo, São Paulo, 2001. 